\title{
Evaluation of Sustainability of Brazilian Ethanol Production: A model in System Dynamics
}

\author{
Arnoldo Jose de Hoyos Guevara ${ }^{\dagger}$ \\ PUC - São Paulo \\ Orlando Roque da Silva ${ }^{\Omega}$ \\ Centro Universitário FMU \\ Haroldo Lhou Hasegawa ${ }^{¥}$ \\ Universidade de Sorocaba \\ Délvio Venanzi* \\ UNISO
}

\section{ABSTRACT}

System dynamics is an approach to analyze the behavior of complex systems, such as the productive chains, strictly considering the inherent characteristics. This approach is based on mathematical concepts of nonlinear processes developed in mathematics and physics and consolidated in engineering. The concepts inherent in this approach assists in creating a mathematical model that represents a production chain by using computer simulation. Thus, the main objective of this paper is to present the formalization of the dynamic model of assessing the sustainability of Brazilian ethanol production. We analyzed the external environment and the scenarios needed for a deeper understanding of relation of cause and effect, causal loops and diagrams of flows and stocks because of the awareness stage, with regard to understanding the problems involved, according to methodology known as design science.

Keywords: Ethanol; System dynamics; Sustainability.

\section{INTRODUCTION}

\subsection{ETHANOL PRODUCTION IN BRAZIL}

The Brazilian supply of ethanol grew in the period 1994-1998 when a crisis period began due to high inventory levels and a fall in the domestic market. During this period the price of sugar in the international market had increased and consequently the supply of ethanol in the domestic market plummeted. With the fall in demand, the market share of ethanol-powered vehicles decreased from $75.5 \%$ in 1985 to $0.06 \%$ in 1997, with high financial and tax costs. This picture has reversed since 2001, when ethanol engines began being manufactured again. This trend has given rise to the emergence of a new ethanol industry since 2003 when flexible fuel engines reentered the market.

The Brazilian sugar and ethanol industry gathered in the biennium 2012/2013, 602 million tons of sugarcane in 8.5 million hectares. Production accounted for 38.8 million tons of sugar and 23.9 billion liters of ethanol. This represents a share of $41.8 \%$ in the total ethanol world production, estimated at 49 billion liters. It is expected for Brazil
Corresponding author:

† PUC - São Paulo.

E-mail:dehoyos@pucsp.br

$\Omega$ Centro Universitário FMU.

E-mail: orlando.silva@fmu.br

¥ Universidade de Sorocaba

E-mail: haroldo.hasegawa@prof.uniso.br * UNISO.

E-mail: delvio.venanzi@prof.uniso.br

Received: 02/02/2016.

Revised: 04/06/2016.

Accepted: 04/06/2016.

Published Online: 12/01/2016. 
to double the sugarcane cultivation area in the next twenty years reaching a production of 40 billion liters of ethanol.

Despite the picture above, the ethanol produced from sugarcane has recently became the subject of intense attacks by European authorities. They see the expansion of biofuel production around the world as the reason for a rise in food inflation. The United Nations (UN) sentenced the biofuels, with the Special Rapporteur statement of the High Commissioner for Human Rights, that mass production is a crime against humanity due to its impact on world food prices. According to Oliveira (2009), through the expansion of biofuels the following question remains: what are the consequences for food production in Brazil with the expansion of the sugarcane crop in the next 20 years?

Data from the Brazilian Institute of Geography and Statistics (IBGE), between 1990 and 2012, show that the reduction of food production, imposed by the expansion of planted area of sugarcane, grew in this period, more than 2.7 million hectares. By taking into account the municipalities that had the expansion of more than 500 hectares of sugarcane in that period we verify that there was a reduction of 261 thousand hectares of beans and 340 thousand hectares of rice. This reduced area could produce 400,000 tons of beans, i.e., $12 \%$ of the national production, and a million tons of rice, the equivalent to $9 \%$ of the country's total. In addition, in these municipalities the milk production was reduced to 460 million liters and the amount of cattle was reduced by more than 4.5 million.

The state of São Paulo, in 2006/2007, cultivated 3.8 million hectares of sugar cane, representing $61 \%$ of the total national sugar cane area. In the same year, it produced $61.5 \%$ of ethanol (10.9 billion liters), $65.8 \%$ of sugar and $61 \%$ of sugar cane from national total production. In 2007/2008, the prospect was a national production of 20.5 billion liters, and São Paulo would participate with 12.7 billion liters, about $62 \%$ of the total. In 2015 , its participation would decrease to $54.9 \%$ due to availability and much lower cost of land in other region. This decentralization, will depend on mid-west logistics for product transportation, as the Transpetro's ethanol pipe from Senador Canhedo, GO, linking Guararema, and from there, linking São Sebastião harbor, in São Paulo State.

Global sugar cane ethanol supply is in expansion as other nations are wakening for this lower cost renewable fuel, while the United States are increasing the production of corn ethanol, with a higher cost. However the drivers of this process of the global supply Market are much more related to the amount of investments in science and technology for the next generations of ethanol production from many other sources of biomass. Therefore, the competitive advantage of countries that rely only in the availability of land and sun light and the actual ethanol technology is not guaranteed in the long run.

Nevertheless, the role of technology in transferring sugar cane processing into biofuel still has the important argument of creating an ethanol international supply market, decreasing risks for traders and users. However, as history shows, global markets of many other agribusiness commodities have being developed along the last centuries and problems of supply (lack and excess), protectionism, and crises are still happening. But the increase of a renewable source of energy will be inexorable, as the investments in production, from the global agribusiness players: traders, logistic operators, mills corporations, regarding mills acquisition, joint ventures and fusion strategies, obtaining advantages with knowledge, supply, economies of scale, market power, transaction costs reductions and risk management. As a result of this dynamic, the Brazilian domestic production for fuel hydrated and dehydrated ethanol in 2006 was 19 billion liters. The consumption as fuel for vehicles comprised of 14 billion liters, 3,6 billion liters were exported and 1,4 billion liters were for domestic industrial use.

Despite the production of ethanol being studied in various universities, research institutions, government agencies and the private sector, regional production and distribution 
BBR

14,4

characteristics have not been sufficiently addressed in research, but are essential to assess the risks and the consequences of such expansion in the environment and in food production.

The picture above associated with the fact that the simulations make it possible to observe the risk factors more clearly than it is possible in real scale, given the complexity of the production-distribution processes, justifies the development of a dynamic model of production based on dynamic ethanol system. In this simulated microcosm becomes possible to isolate the effects and causes more easily than when engaged by the complexities of the real world. (WARREN, 2008).

\subsection{PUBLIC POLICY PROSPECTIVE ANALYSIS}

The literature of prospective analysis describes applications for science, technology and innovation planning, business strategies and governmental policy. The methodological path discussed in this section describes a broad range framework of techniques, highlighting linkages among them, which were used in the prospective ongoing process that will be described in the end of this section.

Prospective studies aim to obtain information in order to give information to help to decide about future events, anticipate and understand the mechanisms, potentialities, evolution, characteristics and effects of innovation processes, institutional and technological change (COELHO, 2003; ZACCKIEWICZ and SALLES-FILHO, 2001). Technological prospective exercises and its various analysis tools can be important instruments for the focalization of primary needs and the identification of knowledge gaps to be filled by research institutions and therefore their resource allocation. Foresight is a multidimensional process to understand the long term future drivers that have to be taken into account to policy, strategy, planning and decision formulations (COATES et al, 2001). It uses qualitative and quantitative methods for monitoring signs and trend indicators of an evolving issue.

Coelho (2003) considers intuitive methods based on specialist assessment are more suitable and cover a broader range of applications in this approach. Although, foresight per se doesn't define policies, it can develop visions about how the future could be built, and suits better when applied to policy analysis and its implications, helping policies to be more robust and flexile in its implementation according to the time line and changing conditions. However, these foresight processes are increasingly complex and new techniques are being applied to decrease complexity in the foresight, by constructing roadmaps (SARITAS and ONER, 2004).

Road mapping is a planning framework (PHAAL, FARRUKH\& PROBERT 2004) which has been used by a broad range of purpose applications including to support strategic and long-range planning intraorganization, inter-organizations (industry), from the private sector science \& technology driven to the state-owned companies and governmental policy agencies. It is a systemic approach used by Garcia and Bray, (1997) for a live monitoring instrument which provides a tool for linking the environment scanning with scenario planning (SCHOEMAKER, 1995) and other prospective techniques. It also links drivers` evolution and inter-relation on markets, products, technologies, knowledge, resources and policy development and implementation in a time line. A policy road mapping process can deal with different levels of future drivers: macro socio-technical transitions and institutional changes, industrial organization, supply-chain interaction and science organization. A roadmap can link these levels of analysis to business/industry sustainability threats and opportunities and the policy formulation agenda. It also links impact analysis and ranks the eligible paths according to the evolving future.

In the case of public policy formulation and road mapping process, the knowledge flows are of two types: one "pull" driven process, in which requirements of knowledge and research are identified and resources are allocated for a long term problem solving 
approach; the other is a "push" driven process where knowledge and capabilities are allocated to influence and establish the policy formulation process and content for a short term problem solving approach. Porter et al (1991) classify families of prospective methods that are described according to their refinement, information availability and treatment. Creativity is a technique for knowledge interaction and generation of a great volume of new ideas.

Specialist panel detects tacit knowledge and weak signs, therefore, it brings ambiguities and is used when information can't be quantified or modeled. Monitoring and intelligence systems are sources of pre-organized information for identifying critical trends and events, their relations, opportunities and threats. However, it provides a great quantity of information from several sources, and when poorly managed, it can result in non-systematized, nonanalyzed, non-selective information excess. These scenario aim to build alternative future pictures, analyzing dominant trends and disrupting possibilities, in a explorative or normative approach. Evaluation and decision are methods to decrease uncertainty complexity when multiple interests and dimensions are being taken in account.

Participative methods have became the key of prospective processes due to the application of its implicit democratic approach, conferring social legitimacy to results and have the ability to involve a diversity of participants, creating collective arrangements, searching for harmonic decision and implementation process. Other important major aspect is the fact that knowledge construction has more effectiveness when there is interaction of knowledge dispersed among participants of an innovation process, and strategic information is widespread among key people involved. Due to these characteristics, they have an interesting appeal on methodology management. Impact assessment can be complementary when this activity is based on scenarios built by the prospective phase.

\subsection{APPLICATION OF SYSTEM DYNAMICS TO SUSTAINABILITY STUDIES}

System dynamics is an approach to analyze the behavior of complex systems, such as supply chains, strictly considering the inherent characteristics. This approach is based on mathematical concepts of nonlinear processes developed in mathematics and physics and consolidated in engineering. The concepts inherent to the methodology aid in the creation of mathematical models representing the productive chain and may diagnose problematic points in chain structure using computer simulations employing an easy to understand representation.

The discovery that mental models influence the way people see the reality has, without doubt, directed the use of system dynamics more on order of explanation of thinking about reality than obtaining numerical answers for well-structured problems (DAVIES, 1996). In this sense, the most important in system dynamics of process usage is to produce insights during the modeling process, strongly identified idea to the creation of knowledge and perception of new opportunities, which according to De Geus (1994), a former executive of Shell. This fact puts the system dynamics from a different perspective from traditional analytical and econometric methods, placing it in the heart of the practice and theory of organizational learning, as postulated by Senge (1990) in his book "The Fifth Discipline".

Agarwal and Shankar $(2005,2008)$ argue that due to the causal relationship, existing in the production system, the approach of dynamic systems is well suited to capture the impact of the dynamic performance of the variables on the integration and responsiveness of the production system in a given time interval.

Researches on systems dynamic applied to sustainability studies are divided into three major groups: 
BBR

14,4

i) Researches that contribute to the construction of theories about sustainability;

ii) Researches using the system dynamics in solving sustainability problems;

iii) Researches working in the development and improvement of modeling tools in sustainability.

The research of Eberleinand Chichakly(2013) is a typical example of the use of systems dynamic in theory construction. Studying the IT service industry Minis et al (2010) proposed a new theory for the virtuous and vicious cycles, using an exploratory causal model to describe the interrelationship of the key success factors.

Morecroft (2007) uses dynamic systems to solve strategy problems by developing a strategy management model for simulating several scenarios. Cha, Pingry and Thatchen (2008) investigated the amplification of demand in supply chains.

Research on the development and improvement of modeling tools in dynamic systems are an example in the work of Howick and Eden (2004) that studied the nature of discontinuities in system dynamics modeling of the disrupted project. Another paper on the line is Arango and Osorio (2009), which considers also the technical, organizational complexity inherent to the system dynamics model for the world coffee market. The System Dynamics offers a suitable framework to accommodate various elements involved and the relationships between them, to integrate them seamlessly in a model that shows in a clear way the weaknesses of current policies and the possibilities of change.

\section{RESEARCH METHODS AND PROCEDURES}

\subsection{RESARCH AIMS}

The main aims from this study are to:

1. Identify the main variables, flows and stocks and the causal relationships of sugarcane, sugar and ethanol production processes;

2. Explore how the production of ethanol in Brazil is increasing and how this production is affecting food production;

3. Apply the modeling and simulation in system dynamics in ethanol production system.

The knowledge generated by this study allows for a more thorough discussion of the ethanol production impacts both on the environment and on food production as well as being the basis for the development of the equations that describe the behavior of variables and stocks that are at the root of the simulation process. The study concluded that beginning with the identification and characterized the elements for modeling and working with different scenarios simulation is better to understand the degree of sustainability of ethanol production.

Thus, the main objective of this paper is to present the formalization of the dynamic model of assessing the sustainability of Brazilian ethanol production, its borders (external environment) and the scenarios needed for a deeper understanding of cause and effect, causal loops and diagrams of flows and stocks.

\subsection{METHODS}

The methodological framework of a research comprise in the selection and justification of a method that is able to respond to the formulated research problem, to be evaluated by the scientific community and demonstrate procedures that make robust research results. These logical steps should not be seen as obstacles to the conduct of research, but as procedures necessary to ensure the impartiality, accuracy in work performance and the reliability of results. Thus, this research adopts the science design methodology. As this research seeks to develop an artifact (dynamic model) to design science proved to be an 
appropriate methodology, not only dealing with the construction of an artifact but also requiring the application of rigorous methods, both in construction and in the evaluation of the product design. Accuracy is often measured by the adherence of the research to an appropriate collection of data and the correct technical analysis.

To identify the variables of the model and the causal relationships, we conducted an interviewin the months of August and September of 2014, with a group of ethanol producers of local productive arrangement of alcohol (APLA) in Piracicaba, SP. The analysis of these interviews has concluded awareness stage with regard to the understanding of the problems involved, according to the science design methodology. Romme and Damen (2007) argue that it may be necessary to understand the issues from a broader perspective, in which systems thinking (ANDRADE et al., 2006), for example, could bring a significant contribution.

\section{RESULTS AND DISCUSSIONS}

In this section we discuss the overview of the model, the causal loop diagram, the diagram of stocks and flows of ethanol production and simulation scenarios. It is used to visual system dynamics modeling tool Vensim ${ }^{\circledR}$, software provided by the company Ventana System Inc., which enables the analyst to link words with arrows representing relations between the variables as causal relationships. The stock diagram and flow in Vensim $^{\circledR}$ consists of auxiliary or constant, cash flow variables that represent actions or accumulations. To complete the modeling process the equation editor uses this information.

\subsection{OVERVIEW OF THE MODEL}

In the model, sugarcane production is considered as the most important production source, while the production of ethanol and sugar is the second level and the generation of solid waste and wastewater is the third level. The figure 1 is a schematic representation of product flows and inventory information associated with ethanol production. The model doesn't include the second-generation ethanol production, from sugarcane bagasse, because the amount of ethanol produced with this technology is small and doesn't influence the data for simulation.

The availability of land for planting treated as being shared between sugarcane and food production, that is, it is considered a finite availability of land so that an increase in planting sugarcane implies the reduction in food crops. The planted crop productivity level influences these increases and decreases. The amount of ethanol to be produced is influenced by the production of sugar, which competes in the consumption of sugar and productive resources, as well as by the level of consumption of other types of fuel such as gasoline and vehicular natural gas, in addition to suffering influence of investments in production and distribution infrastructure.

\subsection{MODELING}

Modeling a system using the system dynamics is interactive and it is an ongoing process of formulating hypotheses, testing and reviewing of formal mental models. According Sterman (2000), in modeling process a few steps should be considered, such as:

1. Problem Articulation - What is the problem? Why this problem? What are the key variables and concepts that should be considered? What time should we considered for the future? What is the historical behavior of the concept and key variables?

2. Formulation Dynamics Hypothesis - Produce initial hypotheses, formulate hypotheses to explain the dynamics and consequences of endogenous feedback 
BBR

14,4

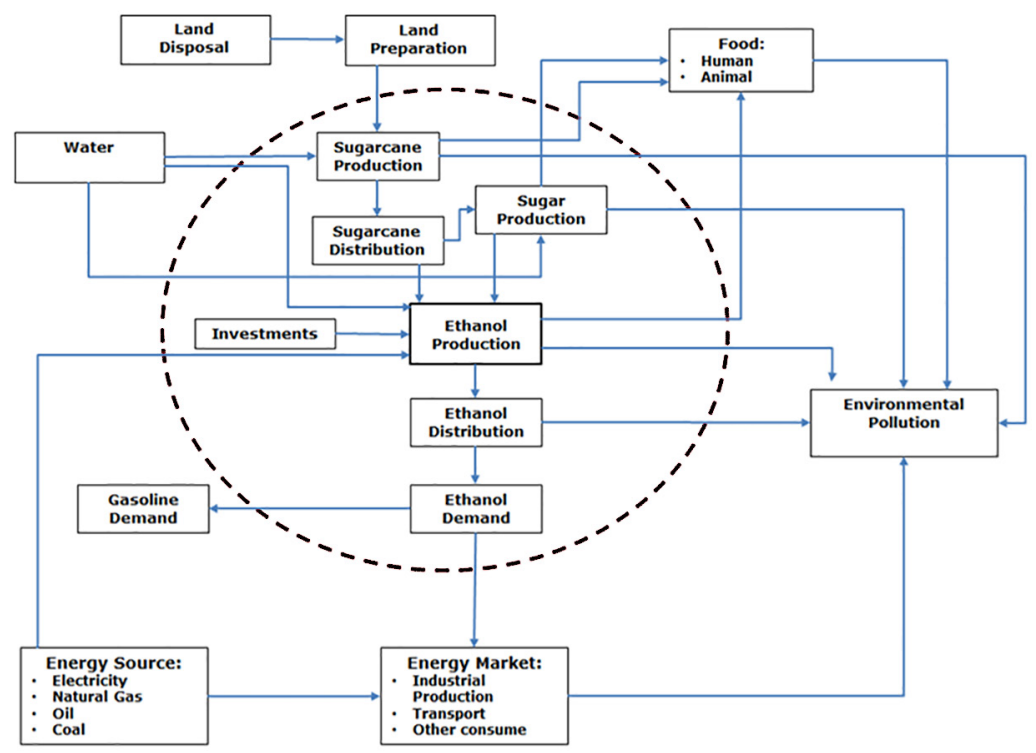

Figure 1. Overview of the ethanol production model.

structure, develop maps of causal structures based on initial assumptions, key variables and other data available;

3. Formulation Simulation Model - Specification of the structure and decision rules, parameter estimation, behavioral relations and initial conditions, tests for stability with objectives and limits;

4. Testing - Does the model adequately produce the proposed behavior? Does the model behave realistically when subjected to extreme conditions? What is the sensitivity of the model?

5. New Policies and Evolution - What environmental conditions may arise? What new decisions, strategies and structures can be experienced in the real world? How can these new scenarios in the model be represented? What is the robustness of the recommended policies for different scenarios, considering the uncertainties? How policies interact? Are there any common actions or compensatory responses?

\subsection{SIMULATION}

Simulation is one of the most powerful analysis tools available to people in the design or operation of systems or complex processes. In an increasingly competitive world, simulation has become a powerful tool for planning, design, and system control. It should always be remembered as the last resort, the simulation is now seen as an indispensable troubleshooting methodology for engineers, designers and managers. Simulating is to imagine, the essence without the reality. A better definition for simulation is: the process of designing a model of a real system to conduct experiments with this model, for the purpose of understanding system behavior and/or evaluating various strategies for its operation. Therefore, simulation can be regarded as the construction of a model for the experimental use allowing the representation of a group of items or ideas that enables us to draw parallels or to represent a particular entity or situation. By the end, a model is meant to represent the set of the collection of related elements to work together to complete a set goal.

According to Agarwal \& Shankar (2005), the performance of a supply chain depends on the integration of its trading partners and the ability to respond quickly to market changes. By simulating, the model for assessing sustainability of Brazilian ethanol production wants 
to evaluate the effect of integration and speed of response to changes in sustainability. The dynamics of interactions between the variables related to the integration of cause and effect and speed should show the importance of the behavior of sustainability in different ethanol production scenarios (represent market changes that require quick responses).

\subsection{THE CAUSAL LOOP DIAGRAM}

This diagram shows the interactions and relationships between ethanol production, land use and water consumption, production of sugarcane and sugar. Figure 2 displays the causal loop diagram of the ethanol production system and the factors of influence. The diagram consists of multiple loops that show, for example, the production of sugarcane, sugarcane price, the government tax incentives, demand for ethanol and gasoline prices affect the production of ethanol.

Thus an increase in ethanol production influences reduction in the price which can increase the demand resulting in the increasing of the price. But an increase in the price reduces the demand for ethanol, hence the negative polarity of the link arrow. Once you have a reduction in the price of ethanol, there will be an increased demand for ethanol followed by the gap between the demand and supply of ethanol respectively. This can lead to both an increase of investment in ethanol and more allocation of sugarcane to produce. An arrow closes the cycle of positive polarity since an increase in the allocation of sugarcane to produce ethanol mean an increase in ethanol production. This cycle is an example of a positive self-reinforcing process.

However, the cycle would prevent the levels of each factor from increasing indefinitely, because other factors beyond the loop, as the ethanol demand influence the price of ethanol. Gasoline demand also influences the demand for ethanol too.

Another example, an increase in yield obtained with the production and commercialization of ethanol positively affects new investments for the production of ethanol increases and the allocation of sugar for ethanol production. The effect of this is to increase ethanol production and decrease the price of ethanol by the forces of supply and demand. An ethanol lower price may reduce the profitability affecting investment levels. This subsystem tends to be inherently unstable if the acting forces do not take the self-regulation condition.

From the causal loop diagram is noticed that relevant factors for ethanol production level as investments in production, allocation of sugarcane production and profitability has a degree of dependence on production efficiency, the price of ethanol and sugar production, the availability of land for planting that can profoundly affect the needs for food and water production growth becoming unsustainable at expected levels.

\subsection{STOCKS AND FLOWS DIAGRAM}

the equations that demonstrate the relationship between factors will be built on the basis of production data and investments of sugar and alcohol sector provided by the Department of Agriculture of the State of São Paulo, by the Council of sugarcane producers, sugar and Alcohol of the State of São Paulo and the Ministry of Agriculture.

The model is built considering four steps. The first step is the focal element ethanol and describes the dynamics of supply and demand, or deal with the production, storage and distribution of ethanol. The second stage, additional production, comes from sugar production model as a product substitute for ethanol production. The third step deals with the modeling of water consumption at various stages and land used for the production of sugarcane and food. The fourth step models the dynamics of capital, costs and investments. The forecast period begins from 2016 and extends until 2035. With this information it is possible not only to simulate the dynamic behavior of the production of ethanol, sugar and 


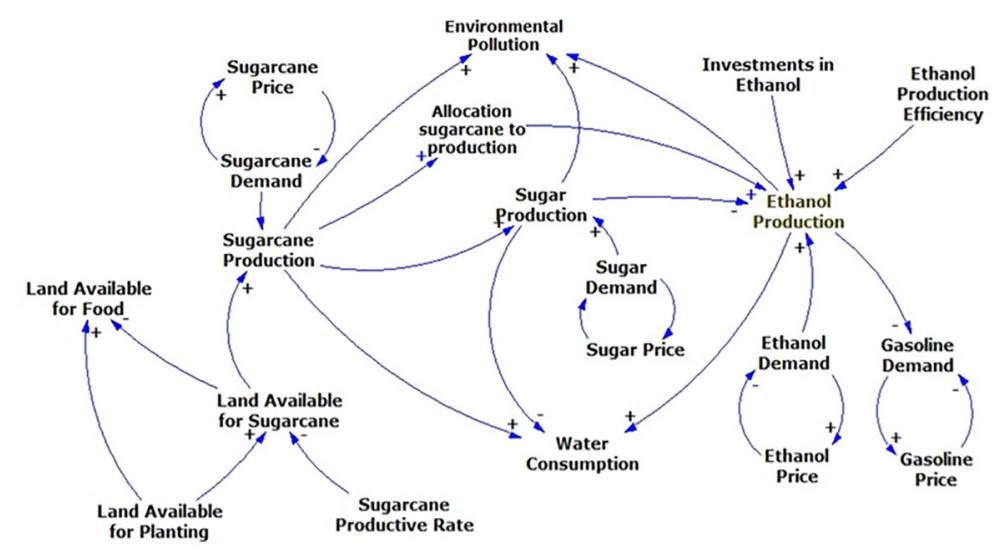

Figure 2. Conceptual model of ethanol production.

sugarcane as well as evaluate the impacts on the environment, water consumption and food production, as illustrated in figure 3.

The flow diagram of inventory threats not only the direct demand for ethanol but also indirect demand processes resulting mixture of ethanol and gasoline constituting a "pull production" by the demand. On the other hand, sugarcane harvesting system is modeled as a system "pushed" in which the sugarcane is harvested and destined for processing. In the case of the demand for sugar being less than the expected, there is no formation of a reserve stock for a short period of time to keep it in delaying the harvest field. If demand is greater than expected and the plants have available production capacities, as there is no training of reserve stocks, you can bring sugarcane from other states since the price and shipping cost offset. In this case, the availability of sugar would be the limiting factor for ethanol production.

The demand of sugarcane for other purposes or sugar production and other industrial applications is shaped according to the projection. The sugarcane allocated to ethanol production depends on the demand, availability and price which in turn depend on the rate of acquisition of sugarcane for ethanol production. If the acquisition rate increases, the price rises and vice versa.

The diagram of stocks and flows also considers demand for ethanol and production capacity increase in the plants in proportion to the amount of sugarcane harvested, increasing the demand of growing areas, occupying spaces before intended for food crops such as rice, beans and corn. Investments in improvements in productivity to obtain the highest percentage of sucrose, exceeding 9\% margin, allow the increase of ethanol production without an increase in the same proportion planted areas. This will appear in the diagram as a mitigating factor for consumption land available for planting.

One answer that is expected with this production simulation model is to evaluate how long production remains sustainable in the face of growing demand for ethanol.

\subsection{COMPUTATIONAL MODEL}

Once modeled in Vensim ${ }^{\circledR}$ the causal loop diagrams and charts of stocks and flows, the computer model will require the introduction of the equations that will govern the causal relationships of the different variables used and the definition of simulation parameters such as unit time to be used and the simulation horizon.

The simulation will work with a set of scenarios to assess the behavior of the variables and the sustainability of production. In the simulation three scenarios apply: an optimist, 


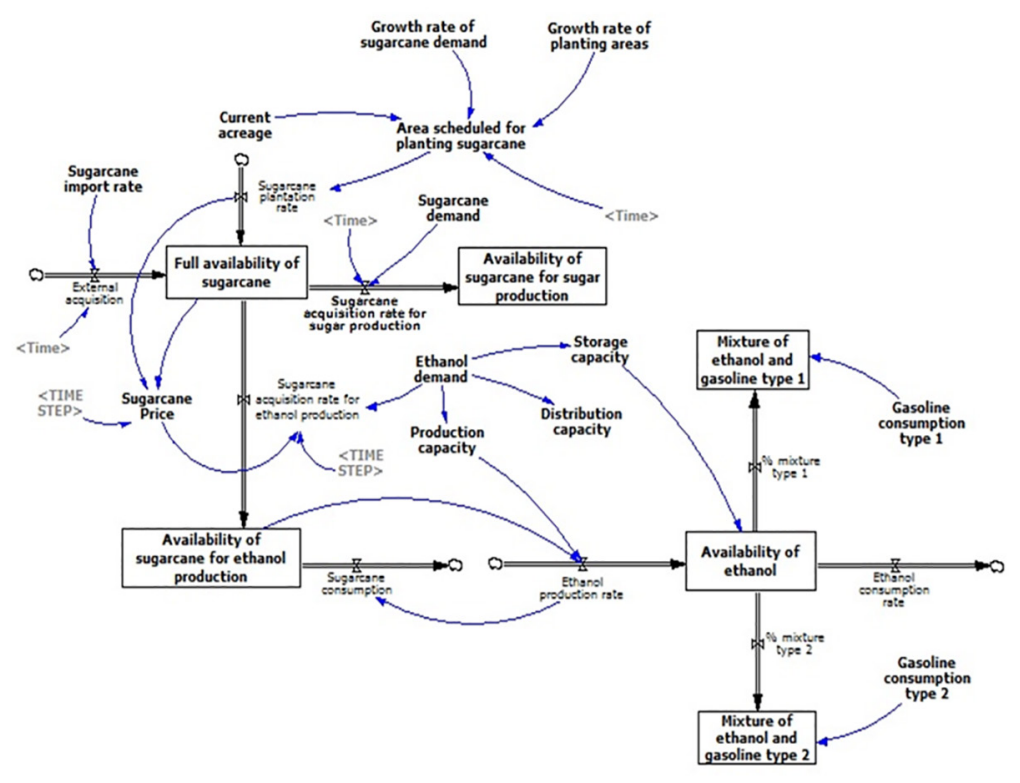

Figure 3. Stocks and Flow Diagram.

a pessimist and more likely. In the first scenario, it is assumed that the first period of 120 months, changes in demand and other factors have stable growth rates. In the second scenario, changes are introduced in the plant's production capacity, oscillating demand for ethanol, water scarcity and fluctuations in the price of the final product, while the other factors remain unchanged. In the third, it's contemplated a scenario in which demand, production capacity, price and production of sugarcane tend to stabilize in the second half of the simulation time.

The computer model allows the interface with other tools such as geographic information systems to display the variations in plantation areas in the form of maps, as well as promote and export data for processing by other computational tools.

\section{LIMITATIONS OF STUDY}

This article discusses the use of system dynamics modeling to model the problem of sustainability of the ethanol production system. The system dynamics modeling appears to be a useful tool for creating scenarios for such problems. However, this article considers some limitations to the use of this specific tool for modeling ethanol production. These limitations are highlighted by the ideas of system theory and by complex science (BOSSEL, 2007). There are also fundamental limitations to the correct prediction of the sustainability of ethanol production in the next twenty years, which are made clear by critics from of current production system (DeTOMBE, 1994) and chaos theory (GLEICK, 1987). These restrictions, however, do not set aside the importance of modeling and simulation tools as aid in understanding of dynamic phenomena such as sustainability.

\section{CONCLUSIONS}

As Mendonça (2007) pointed out: "Not long ago, biofuels were feted as an alternative to save the planet from carbon dioxide accumulation and excessive dependence on oil [...] were the synonym of a new era, the era of clean where the energy sources must be in tune with the environment $[\ldots]$ ". But, with so many contradictions, "[...] the wind shifted radically. Biofuels, almost overnight, is being considered the villain of the planet, responsible for the current food crisis, by soaring prices". 
BBR

14,4

This article presented the step of formalizing the model for assessing the sustainability of ethanol production, its borders (external environment) and satisfactory solutions necessary to study the Brazilian ethanol production, its effects on the environment, food production and water consumption and future trends in three different simulation scenarios.

The model considers that the importance of energy independence cannot be overestimated. Oil prices are expected to grow in coming years, as reserves are depleted and the remaining oil extraction process becomes more expensive. Ethanol is a biofuel which has an excellent history of use and relative ease of production as the basic raw material is sugarcane which can be easily cultivated. As a result, sugarcane production is expected to increase and more processing plants to be set up.

Improvements in farming technology are expected to increase productivity per hectare. However this increase can mitigate but not stopping the increase in sugarcane growing areas and hence bring significant reductions in food production with serious implications for the use of sugarcane as an alternative form of energy.

The use of modeling allows us to work with simulation scenarios and conditions where it is possible, given the initial conditions and the quality of the model, assess what would happen to the ethanol industry if ethanol prices float in response to the availability and supply of alternative energy sources for transportation or what would happen to food prices if ethanol demand continues to grow at an increasing rate. The model should be able to allow the situation of research that changes in planned production of sugarcane, the prices of sugarcane, capacity, demand and other factors relevant to the industry that can become business continuity unsustainable, either by lack of water resources or by the need of production and food for a growing population.

The sugarcane industry has increased sugarcane production due to economic pressures and due to increased demand for ethanol produced from sugarcane, in large part, by the introduction of automobiles that consume ethanol market. On the other hand, the use of intensive technologies in the production units, to increase productivity in the field, creates dependence on external inputs compromising their economic sustainability. Climate change projections indicate that the sugarcane production systems will be affected by rising temperatures and drought, among other extreme weather events.

The increase in the responsiveness of the sugarcane production system to adverse weather events is increasing system resiliency. Like resilience is the potential of a particular arrangement of a production system to maintain its structure and function when a disturbance occurs, it became the biggest challenge that the sugar-alcohol sector will face in the coming years. Exploring the concept of resilience enables us to better understand and plan actions towards sustainability of sugarcane production systems. In this scenario, the following problems arise: identify the types of production systems, provide agricultural land to meet the increasing demand for sugarcane, identifying the types of production systems that will supply the growing demand for sugarcane, creating mechanisms to minimize price volatility, mainly avoid higher costs in cases of extreme weather events; identification of new technologies for sugarcane planting and sugarcane harvest, identify relevant data and new technologies to production systems of ethanol to maximize the performance of production units.

The models are as useful as the data used in their construction, understanding of the analysts and the inclusion of important and relevant factors. Brazil is the leading producer of large-scale biofuels and, maintaining this leadership depends on largely sustainability of ethanol production. As such, an evaluation model of sustainable production will be useful to explore the changes in market trends, assessment of impacts of new technologies of production and genetic improvement of sugarcane constituting a research instrument for the assessment of the future impacts of production biofuels in Brazil. 


\section{REFERENCES}

AGARWAL, A., SHANKAR, R., Modeling supply chain performance in different market scenarios. Proceedings of the $23^{\text {rd }}$ International Conference of the System Dynamics Society. Boston, USA: The System Dynamics Society. 2005.

AGARWAL, A., SHANKAR, R., 2008. Modelling integration andres ponsiveness for supply chain. Proceedings of the International Conference of the System Dynamics Society. Athens, Greece: The System Dynamics Society. 2008.

ANDRADE, A. L. et al., Pensamento Sistêmico: Caderno de Campo. Bookman, Porto Alegre.2006.

ARANGO, S., OSORIO, F. A. A system dynamics model for the world coffeemarket. The $27^{\text {th }}$ International Conference of the System Dynamics Society, Albuquerque, New Mexico, USA: System Dynamics Society. 2009.

BOSSEL, H. Systems and Models: complexity, dynamics, evolution, sustainability. Books on Demand, Norderstedt, Germany. 2007.

CHA, H.S., PINGRY, D.E., THATCHEN, M.E. Managing the know ledge supply chain: anorganizational learning model of information technology off shore out sourcing. MIS Quarterly Vol. 32 No. 2, pp. 281-306/June.2008.

COATES, V., FAROOQUE, M., KLAVANS, R., LAPID, K., LINSTONE, H.A., PISTORIUS, C. \& PORTER, A.L. On the future oftechnological fore casting. Technological Forecastingand Social Change Vol 67, n. 1, p. 1-17, 2001

COELHO, G.M. Prospecção tecnológica: metodologias e experiências nacionais e Internacionais. Rio de Janeiro, Projeto CT-Petro, 2003. Disponível em: <http://www.tendencias.int.gov.br./>. Acesso em 05 de agosto de 2014.

DAVIES, Stuart. Producing a forwardplan, MGM Guidelines For Good Practice. Londres: Museu mand Galleries, 1996.

De GEUS, A. P. Modeling to predictor tolearn? In: MORECROFT, J. D. W; STERMAN, J. D. (Eds.) Modeling for learning organizations. Portland: Productivity Press, 1994. p. xii-xvi. (System Dynamics Series).

DETOMBE, D.J. Co-operative Handling of Complex Interdisciplinary Societal Problems. In Guang zhong Liu, Kang-Hoh Phua, Jigang Ma, Juping Xu, Fuwen Gu \& Changzheng He (Eds.) OptimizationTechnique sand application, ICOTA '95, vol. 2. Chendu University of Science and Technology, Chengdu, China. Singapore, New Jersey, London, Hong Kong: World Scientific, pp. 1408-1416.1995.

EBERLEIN, R.L., CHICHAKLY, K.J., 2013. XMILE: a new standard for system dynamics. System Dynamics Review 29(3), 188-195

GARCIA, M.L. and BRAY, O.H. Fundamentals of technology road mapping. Report SAND97-0665, Sandia National Laboratories. 1997.

GLEICK, J. Chaos: making a new science. New York: Viking.1987.

HOWICKS, S., EDEN, C. On the nature of discontinuities in system dynamics modelling of disrupted project. Journal of the Operational Research Society 55, 598-605.2004

MENDONÇA, M. R. Bioenergia e viabilidade da produção de alimentos: para quem? Revista Formação, n. 15 volume 2. São Paulo, p. 189-226.2007.

MINIS, I., ZEIMPEKIS, V., DOUNIAS, G., AMPAZIS, N. Supply Chain Optimization, Design, and Management: Advances and Intelligent Methods. IGI Global, New York.2010.

MORECROFT, J. D. Strategic Modelling and Business Dynamics: A feedback systems approach. John Wiley \& Sons, London. 2007.

OLIVEIRA, A. U., 2009. Os agrocombustiveis e os alimentos. Disponível em:<http://egal2009. easyplanners.info/area06/6194_OLIVEIRA_Ariovaldo_Umbelino.doc.> acesso em: 05 de agosto de 2014.

PHAAL, R., FARRUKH, C.J.P. \& PROBERT, D.R. Technology roadmapping - A planning frame work for evolution and revolution. Technological Forecastingand Social Change Vol 71, n. 1-2, p. 5-26, 2004

PORTER, A. L., et al. Forecasting and management of technology, New York: Wiley Interscience, 1991.

ROMME, A. G. L.; DAMEN, I. C. M. Toward science based design in organization development. The Journal of Applied Behavioral Science, v. 43, n. 1, p. 108-121.2007.
BBR

14,4 
BBR

14,4

447

SARITAS, O. ONER, M.A. Systemican alysis of UK foresight results: joint application of integrated management model and road mapping. Technological Forecastingand Social Change71 (1),p.27-65, 2004.

SENGE, P. M. A quintadisciplina. 12.ed. São Paulo: Best Seller, 1990. 351 p.

SCHOEMAKER, P. J. H. Scenario Planning: a tool for strategicthinking. Sloan Management Review. Winter, 1995.

WARREN, K., 2008. Strategic Management Dynamics. John Wiley \& Sons, London.

ZACKIEWICZ, M. SALLES-FILHO, S. Technological Foresight - Um instrumento para politica científica e tecnológica, Parcerias Estratégicas, n.10, março, p. 144-161, 2001. 